\title{
Sociologia do desvio e interacionismo
}

\author{
RITA DE CÁSSIA PEREIRA LIMA
}

RESUMO: Este artigo é essencialmente teórico e tem como objetivo apresentar uma análise histórica não exaustiva da sociologia do desvio, privilegiando as teorias interacionistas. Inicialmente, após um breve relato sobre a aparição da sociologia do desvio em Chicago, serão comentadas três tendências que buscam analisar as causas do desvio: o funcionalismo, a anomia e o culturalismo. Em seguida, o interacionismo surge como uma proposta de rompimento com o enfoque causal. A especificidade da teoria interacionista, particularmente a "Labelling Theory" de H. Becker, encontra-se na ação coletiva e na ênfase no processo social através do qual um indivíduo ou grupo é considerado desviante pelos demais. Para finalizar, serão mencionadas algumas tendências mais recentes, por exemplo, a fenomenologia e a etnometodologia, acrescidas de algumas críticas dirigidas ao conjunto dessas teorias, especialmente por Pierre Bourdieu.

\section{Aparição e evolução da sociologia do desvio}

ste texto não tem a intenção de realizar uma análise detalhada e exaustiva sobre a teoria interacionista. As reflexões teóricas apresentadas têm como referência empírica as reflexões decorrentes da tese de doutorado da autora, cujo objeto de pesquisa refere-se às práticas diagnósticas das equipes interdisciplinares da FEBEM-SP ${ }^{1}$. O artigo é destinado, principalmente, aos que se interessam pela questão do desvio. Espera-se que a complexidade intrínseca às idéias propostas no texto possa estimular os
PALAVRAS-CHAVE: sociologia do desvio, interacionismo, labelling theory.
Professora da Faculdade de Medicina da UNAERP 
${ }^{1}$ Este texto inspira-se no Capítulo III da tese de doutorado da autora, intitulada $O$ processo de elaboração de diagnósticos de crianças e adolescentes 'abandonados', 'infratores' $e$ 'assistidos' pelas equipes interdisciplinares da Fundação Estadual do BemEstar do Menor de São Paulo (FEBEM-SP), defendida na Universidade René Descartes-Paris V, em 1994. O trabalho contou com o apoio financeiro do CNPq.

A data entre colchetes refere-se à edição original da obra. Ela é indicada na $1^{\mathrm{a}}$ vez que a obra é citada. Nas demais, indica-se somente a edição utilizada pelo autor (N.E.). leitores a aprofundarem teoricamente os temas abordados, os quais estão relacionados a diversas situações que envolvem o fenômeno do desvio na sociedade.

Considerando-se a diversidade e abrangência das teorias sobre o desvio, pode-se tomar como ponto de partida a definição de Downes \& Rock: "a sociologia do desvio não é uma disciplina coerente em seu conjunto, mas uma coleção de versões relativamente independentes dentro da sociologia" (Downes \& Rock, [1982]*1988, p. 1).

Desenvolvida no final do século XIX por autores anglo-saxões, a "sociologia do desvio" aparece primeiramente como uma disciplina que tem por finalidade a conceituação de alguns problemas sociais abordados pelas obras de criminologia, por tratados filosóficos e ensaios religiosos. Antes do século XIX, vários trabalhos em teologia e criminologia já mencionavam as questões morais relacionadas ao pecado e ao crime. Segundo Downes \& Rock, particularmente no século XVInota-se a emergência de um tipo de 'relatório sobre formas inferiores de vida' com a intenção de apresentar informações detalhadas sobre o sub-mundo. Era uma descrição ingênua de ladrões, prostitutas, batedores de carteira, de suas organizações sociais e carreiras, de suas técnicas e relações com as vítimas (Downes \& Rock, 1988, p. 58).

No final do século XIX o departamento de sociologia da Universidade de Chicago assume um papel decisivo na ordenação dos textos, às vezes especulativos, sobre o crime na sociedade americana. O trabalho dessa universidade é fundamental para a história da sociologia do desvio e abre novas perspectivas de pesquisa.

Seria relevante enfatizar o caráter empresarial do departamento de sociologia da Universidade de Chicago, criada em 1892. Alguns autores chegam a dizer que em Chicago a sociologia foi "industrializada"(Downes \& Rock, 1988). Concebida para ser a melhor, essa universidade contava com um orçamento elevado, fruto principalmente de inúmeras doações de particulares.

Para Downes \& Rock, nessa época a sociologia da Universidade de Chicago tornou-se a sociologia da cidade de Chicago, ou seja, um mapa antropológico de todos os seus bairros. Sendo um vilarejo em 1833, Chicago tornase uma cidade notável em 1900. A chegada de imigrantes (irlandeses, suecos, alemães, poloneses e italianos) contribuiu consideravelmente com o aumento da população da cidade. Mas cada um desses grupos foi levado a conquistar seu lugar e enfrentar as dificuldades tentando preservar seu próprio modo de vida. Dessa forma, a vida urbana de Chicago era caracterizada por uma mudança de cenas e de identidades conforme o bairro. Para alguns grupos sociais, o "desvio" tornou-se um modo alternativo de sobrevivência que substituía o modelo tradicional das instituições americanas.

Como observa Coulon, a questão da integração e da assimilação dos imigrantes nos Estados Unidos foi evidentemente central num 
país que progressivamente se constituiu sobre vários sedimentos migratórios, particularmente importantes durante o século XIX e as duas primeiras décadas do século $X X$, período em que se instaurou um debate político intenso, por um lado sobre a questão da americanização dos antigos imigrantes, e por outro lado sobre a oportunidade de continuar a autorizar um fluxo migratório importante (Coulon, 1992, p. 23).

Nesse contexto, as pesquisas sobre o crime e a delinquiência começaram a ser mais específicas e a Escola de Chicago passa a ter um papel relevante sobretudo nos anos 20. No início esses fenômenos eram atribuídos principalmente aos efeitos de isolamento de certas zonas da cidade e considerados uma consequiência do crescimento de Chicago e da estrutura importada pelos imigrantes. Escapando do controle político e desprovidos de recursos econômicos, os primeiros imigrantes geraram sua própria política e sua própria economia. Coulon afirma que:

em Chicago a história da criminalidade é marcada por ondas sucessivas de imigrantes que se instalaram na cidade. Primeiramente alemã e irlandesa no início do século XX, depois polonesa e italiana nos anos 20, e enfim tornou-se hispano-americana e negra trinta anos mais tarde (Coulon, 1992, p. 57).

Em sua origem, os estudos sobre o desvio apresentavam um enfoque "ecológico", apoiando-se em modelos de relações sociais num meio geográfico específico. Alguns autores como Park \& Burgess ([1925], 1979 apud Durand \& Weil, 1990) privilegiaram esse tipo de estudo no quadro da sociologia urbana, analisando o fenômeno da imigração e da desintegração social.

A origem da Escola de Chicago é marcada por essas abordagens espaço-temporais. Em seu conjunto, as análises sociológicas propostas pela Universidade de Chicago se inspiravam no pragmatismo, no sentido em que tanto as idéias científicas quanto as idéias a respeito do cotidiano repousavam na experiência. Tais análises incluíam o modo de vida de alguns grupos sociais, suas relações sociais, a censura de que eram objeto e a punição que eventualmente lhes era infligida por outros grupos sociais.

A maior parte das diferentes correntes teóricas propostas para estudar o fenômeno do desvio são baseadas em princípios ligados às definições de normas de vida em sociedade. Apesar de sua diversidade, um ponto comum as une. Como menciona Faugeron,

o desvio - por mais diverso que seja, e ele o é extremamente-é sempre e essencialmente uma diferença. Todo fenômeno de desvio é colocado sobre - e definido pelo - sinal da diferença. O desviante é essencialmente percebido e representado como sendo diferente do restante do grupo social (Faugeron, 1976, p. 13). 
Considerando-se o conjunto das teorias sobre o desvio, alguns aspectos distinguem o interacionismo (tema deste artigo) das outras tendências. Apesar do enfoque interacionista ser analisado no item seguinte, para melhor entendimento será mencionada aqui a ruptura dessa corrente com outras abordagens, as quais visam particularmente explicar as causas do desvio. Apesar do interacionismo ter rompido com tal orientação, é importante observar que as idéias interacionistas surgiram concomitantemente às outras, porém foram de fato desenvolvidas décadas depois. As análises de Mead já aparecem a partir dos anos 20, constituindo posteriormente as bases das teses interacionistas. A idéia central de Mead ([1934] 1963 apud Durand \& Weil, 1990) é que a sociedade se constrói através da "dinâmica dos atos sociais, ou troca entre as pessoas ou interações" (Durand \& Weil, 1990 , p. 168). Esse enfoque não privilegia as causas do desvio, mas a construção do fenômeno na sociedade através das interações sociais.

Neste item serão abordadas três vertentes teóricas que procuram explicar as causas do desvio: o "funcionalismo", a "anomia" e o "culturalismo". Apesar de certos aspectos similares, elas apresentam algumas particularidades.

Para os teóricos do funcionalismo, a sociedade possui os mesmos mecanismos da natureza, particularmente da vida biológica. A sociedade seria então um "organismo" onde todas as partes devem funcionar em relação com o todo.

Em Da divisão do trabalho social, Durkheim ([1893] 1967 apud Durand \& Weil, 1990) analisa a função preenchida por cada fenômeno social em relação com as "necessidades do organismo social". Segundo Downes \& Rock (1988), essa obra reflete a tendência evolucionista postulada pelos funcionalistas. Por exemplo, na passagem da sociedade agrícola para a sociedade industrial, algumas instituições são vistas como funcionais e outras não.

Inspirando-se nos trabalhos de Durkheim, Merton ([1953] 1965 apud Durand \& Weil, 1990) tenta mostrar a necessidade de um certo equilíbrio da estrutura social. Dentro de um enfoque que alguns chamam "funcionalismo relativizado" ou "moderado", esse autor analisa como a estrutura social pode, às vezes, favorecer o não-conformismo e a adoção de comportamentos qualificados de desviantes. Para Merton, esses comportamentos não resultam de suas condições biológicas, mas são provenientes "naturalmente" da situação social. O autor sugere que certas formas de comportamento desviante são psicologicamente tão normais quanto o comportamento conformista, colocando em questão as noções de "desvio" e "anormalidade".

Na direção oposta, Malinowsky ([1944] 1988) desenvolve a tendência que alguns chamam "funcionalismo cultural" (cf. Downes \& Rock, 1988) ou "funcionalismo absoluto" (cf. Durand \& Weil, 1990). Para ele, as teorias antropológicas devem apoiar-se nos fatos biológicos. De acordo com a teoria funcionalista da cultura, por exemplo, as funções das instituições, das organizações ou das práticas sociais têm relação com uma necessidade biológica. Dessa maneira, todo objeto social possui necessariamente uma função. 
No seu conjunto, as teorias funcionalistas tentam estabelecer uma constituição bio-antropológica ou sócio-patológica da sociedade. Essa corrente é geralmente criticada no que diz respeito à aceitação não-crítica das estatísticas oficiais, à permeabilidade a um sistema de valor uniforme na sociedade e a uma concepção do "desvio" mais patológica que problemática (cf. Downes \& Rock, 1988).

Outro enfoque para analisar o desvio é a teoria da "anomia" durkheimniana ${ }^{2}$, associada aos aspectos da desorganização estrutural e funcional da sociedade. Para Durkheim, o desregramento de uma sociedade corresponde à inadaptação social de seus membros. Boudon \& Bourricaud (1982) constatam que o conceito de anomia não tem exatamente o mesmo significado em O suicídio (Durkheim, [1897] 1960) e em Da divisão do trabalho social (Durkheim, 1967). No que diz respeito ao segundo, os autores analisam o que Durkheim denomina "as rupturas parciais da solidariedade orgânica". Eles observam a descrição de certos fenômenos que aparecem como incompatíveis com a imagem da "sociedade-organismo" inerente a essa noção de "solidariedade orgânica" (por exemplo, as falências, o antagonismo entre trabalho e capital). Quanto a $O$ suicídio, Boudon \& Bourricaud apontam o raciocínio de Durkheim:
o mundo da indústria e do comércio é por essência anômico no sentido em que as normas às quais estão sujeitos os atores sociais lhes deixam uma margem de autonomia. Essa autonomia conduz, no plano co- letivo, aos efeitos de 'ruptura de solidariedade orgânica'(crises) e, no plano individual, à exposi- ção ao risco, à incerteza, eventualmente ao fracasso e à confusão (Boudon \& Bourricaud, 1982, p. 21).

Segundo Downes \& Rock (1988), Durkheim faz dois usos distintos do conceito de anomia. Em "Da divisão do trabalho social", o autor caracteriza o estado patológico da economia. Em "O suicídio", o conceito designa o estado mental patológico dos indivíduos insuficientemente regulados pela sociedade.

Boudon \& Bourricaud afirmam que através das concepções explicitadas nas duas obras pode-se encontrar uma tomada de posição ideológica de Durkheim. Para os autores, a conclusão de Da divisão do trabalho social sugere:

uma sociedade onde os indivíduos seriam guiados por um sistema de valores e de normas, quer dizer, por uma moral, que os incitaria e os convidaria a satisfazerem-se com suas posições no sistema de divisão do trabalho: a noção de anomia evoca, no vazio, o apego de Durkheim ao modelo simplificador e contestável assimilando sociedade e organização, ou seja, sociedade e organismo (Boudon \& Bourricaud, 1982, p. 21).
${ }^{2} \mathrm{O}$ conceito de "anomia", utilizado por vários sociólogos, tem a ambição de traduzir de maneira precisa a noção vaga de desregramento social. Sob um ponto de vista amplo, "anomia" quer dizer ausência de organização natural ou legal. Nota-se a idéia de um desregramento fundamental das relações entre o indivíduo e a sociedade (Boudon \& Bourricaud, 1982). 
A análise de Durkheim sobre o crime ilustra sua concepção sobre a "anomia". Para o autor, o crime é um "fenômeno social normal", relativo à sociedade ou ao tipo de cultura dentro da qual ele se produz. Quando o equilíbrio de uma sociedade é comprometido em conseqüência de uma crise econômica ou moral, certos comportamentos qualificados de desviantes podem resultar do estado de desregramento moral ou econômico dessa sociedade. Como observa Selosse,

as teorias da anomia dão ênfase aos efeitos da desorganização social associados aos desequilíbrios e às desigualdades. Elas ilustram as condições que colocam obstáculos às aspirações dos indivíduos, mas também às perturbações da transmissão do sistema normativo (Selosse, 1981, p. 19).

A "anomia" designa, portanto, a derrota das solidariedades coletivas e caracteriza o enfraquecimento da coesão do sistema social. Nesse contexto, o desvio é encarado como uma consequiência da repercussão dos conflitos sociais sobre as consciências individuais, podendo engendrar a perda do sentido dos valores coletivos.

O terceiro enfoque causal citado anteriormente para abordar o fenômeno do desvio é a tendência "culturalista", desenvolvida notadamente durante os anos 50 e 60. De acordo com essa corrente, a sociedade é dividida em função das diferentes culturas de classe, cada uma com suas próprias normas, crenças e valores. O comportamento desviante é "localizado" num dos setores do sistema social, em conflito com os outros componentes desse mesmo sistema.

Como observam Durand \& Weil, diremos que há conflito de cultura (de valores ou de normas) quando as regras de conduta, mais ou menos divergentes, virão concorrentemente reger a economia de uma ou outra situação particular dentro da qual se encontra, num dado momento, um indivíduo (Durand \& Weil, 1990, p. 501).

Sutherland, Cohen e Cloward \& Ohlin são os principais autores dessa corrente. Com a teoria das "associação diferencial", Sutherland ([1924] 1966 apud Durand \& Weil, 1990) supõe que o comportamento criminoso é um comportamento aprendido através de um processo de comunicação dentro de um grupo restrito. Selosse afirma que nesse aspecto "a passagem ao ato delituoso seria o resultado de um excesso de solicitações de associações favoráveis à violação da lei dentro de um campo de forças antagonistas" (Selosse, 1981, p. 18).

Cohen (1955 apud Downes \& Rock, 1988)tentou definir o modo de vida das "gangs" delinqüientes no contexto urbano e, para isso, sistematizou a utilização dos conceitos de "cultura" e "sub-cultura". O objetivo principal dessa pesquisa foi conceituar o papel da estrutura social e do meio social imediato dos delinqüentes, com a finalidade de propor a criação e a seleção de soluções aplicáveis às "gangs". 
Com inspiração nos trabalhos de Cohen, Cloward \& Ohlin (1960 apud Downes \& Rock, 1988) formularam a idéia que a delinqüência está associada às "estruturas de oportunidades sociais" dos meios urbanos. Dessa maneira, os autores consideram que:

o acesso aos objetivos propostos pela sociedade depende dos recursos sociais legítimos ou ilegítimos da forma como as estruturas os sugerem: a delinquiência parece uma conduta adaptada em certos meios às oportunidades locais (Selosse, 1981, p. 19).

Em geral, as abordagens culturalistas sugerem que as formas de delinqüência mais insensatas e desprovidas de sentido poderiam tornar-se inteligíveis e racionais através da definição da situação dos próprios delinqüentes. Nesse sentido, elas concebem a delinqüência mais como uma solução face aos conflitos do que como um problema social (cf. Downes \& Rock, 1988).

Os três enfoques sobre o desvio citados nesse ítem (o "funcionalismo", a "anomia" e o "culturalismo") privilegiam a análise de suas causas. Os autores têm como objeto de estudo a organização ou a desorganização social para compreender e explicar as causas dos comportamentos desviantes. Dentro de um paradigma normativo, o desvio é encarado mais como uma disfunção da sociedade do que como um problema social complexo envolvendo as interações entre grupos sociais distintos.

O objetivo deste artigo é tomar uma posição crítica em relação aos três enfoques mencionados acima, privilegiando o estudo do desvio como um fenômeno que supõe interações em várias redes de relações sociais. Considerando-se que o desvio é construído por diferentes atores sociais, ele não será analisado isoladamente como conseqüência da desorganização social e do caráter patológico da sociedade ou dos indivíduos desviantes. As teorias interacionistas, analisadas em seguida, expressam esse posicionamento.

\section{As teorias interacionistas do desvio}

Conforme mencionado anteriormente, as teorias interacionistas do desvio se inspiram nas análises psico-sociais de Mead(1963), desenvolvidas a partir dos anos 20 pelo departamento de sociologia da Universidade de Chicago. Essas análises privilegiam o processo através do qual os comportamentos de alguns indivíduos respondem, positivamente ou negativamente, às expectativas dos outros.

A difusão das idéias de Mead foi bastante lenta. Lemert (1951 apud Faugeron, 1976) elabora uma teoria sistemática do comportamento desviante baseada na reação social somente no início dos anos 50. Para o autor, o comportamento não-conforme não seria mais definido pelo ato desviante em si, nem por suas causas, mas pelas reações dos outros.

De acordo com Conrad \& Schneider (1980), existem duas orientações na sociologia do desvio: a positivista e a interacionista. Para os 
"positivistas", o desvio existe na experiência objetiva das pessoas que cometem os atos desviantes e das que respondem a esses atos. Tal tendência visa principalmente procurar as causas do comportamento desviante, que geralmente são descritas em termos de dados sociais e/ou culturais e de características individuais que impedem a socialização do indivíduo. As questões que os "positivistas" colocam sobre os desviantes são: "Por que eles fizeram isso?", "Como podemos fazê-los parar"?

Para os interacionistas, a moralidade de uma sociedade é socialmente construída; ela é relativa aos atores, ao contexto social e a um dado momento histórico. Se essa moralidade não nasce por si, é preciso que haja os "construtores". Dessa maneira, a moralidade pode ser definida pelas pessoas cujas reivindicações são baseadas em seus próprios interesses, valores e visão de mundo. Considerando-se que o desvio é uma definição social, os interacionistas se preocupam com sua construção, com a forma que certos rótulos são colados em algumas pessoas, com as consequiências que tal fato pode engendrar neles e nos que os rotularam assim. As questões que os "interacionistas" se colocam sobre os desviantes são: "Como eles os criaram?", "Quais são as conseqüências?" (Conrad \& Schneider, 1980).

Com esses princípios, as teorias interacionistas do desvio rompem com as concepções mencionadas no item anterior. O desvio e seu controle são agora encarados de maneira dialética, através de um processo de interação dinâmico e variável entre as duas partes. Várias correntes interacionistas foram desenvolvidas, baseadas em tais fundamentos. A mais conhecida é a da "rotulação social" (Labelling Theory), proposta por Becker ([1963] 1985) nos anos 60. Durand \& Weil sintetizam o pensamento do autor afirmando que nessa perspectiva:

\section{o desvio não é simplesmente o fato objetivo de não se conformar com as normas (interpretação funcio- nalista) mas a conseqüência de um rótulo colado nas costas do desviante pelos que o descobrem e o tra- tam (Durand \& Weil, 1990, p. 171).}

A concepção de Becker sobre o fenômeno do desvio privilegia o papel da ação coletiva, cujas regras são impostas por um processo social que define coletivamente certas formas de comportamento como tipos de problemas. $\mathrm{O}$ autor considera o desvio "como o produto de uma transação efetuada entre um grupo social e um indivíduo que, aos olhos do grupo, transgrediu uma norma", interessando-se "menos pelas características pessoais e sociais dos desviantes do que pelo processo através do qual estes são considerados estranhos ao grupo, assim como por suas reações a esse julgamento" (Becker, 1985, p. 33).

O caráter desviante ou não de um ato depende então da maneira que os outros reagem. Segundo as teorias da rotulação, o desvio é o resultado das iniciativas do outro, visto que ele encadeia um processo de intervenções colocado em prática para selecionar, identificar e tipificar os indivíduos. Uma das mais 
importantes contribuições desse enfoque foi chamar a atenção para as conseqüências que implicam, para um indivíduo, o fato de ser rotulado como desviante.

Conforme observa Selosse, "a rotulação pode levar a uma redução de capacidades e acusar o aspecto negativo dos traços atribuídos" (Selosse, 1981, p. 24).O indivíduo considerado desviante pode então evoluir, por um lado, no sentido das previsões do outro e, por outro lado, no dos efeitos da estigmatização que o conduzirão a adotar o estereótipo que lhe foi reprovado na origem. Dessa forma, um comportamento não-conforme pode tender para um status social que integra o desvio (cf. Selosse, 1981).

Um aspecto essencial enfatizado por Becker é que o processo social em que certos indivíduos são definidos coletivamente como desviantes engendra uma nova categoria de problema social. Como conseqüência, métodos de controle são colocados em prática e a institucionalização do "tratamento" das pessoas rotuladas é estabelecida.

Segundo Becker, o desvio é sempre o produto de um "empreendimento", dirigido por dois tipos de "empreendedores de moral": os que criam as normas e os que as fazem aplicar. Os primeiros empreendem uma "cruzada" para a reforma de costumes. Os segundos são os agentes institucionais encarregados de fazer respeitar as novas leis estabelecidas por essa "cruzada". De acordo com Chapoulie,

os estudos interacionistas analisam o conjunto das relações que entretêm todas as partes implicadas de perto ou de longe nos fatos do desvio (e não somente as interações face-a-face, conforme mostra o interesse de Becker pelos 'empreendedores de moral') (Chapolie, 1985, p. 13).

As reflexões de Becker propõem uma mudança de perspectiva. $\mathrm{O}$ autor abandona o "tratamento" das formas de desvio que visam a procura da origem dos atos na psicologia individual dos desviantes ou em seu ambiente sociocultural. Seu interesse principal é o papel dos agentes que contribuem para a definição desse desvio.

Para o autor, julgar que uma categoria de pessoas é exterior à coletividade implica um certo poder, legitimado pela organização política e econômica. O sucesso do processo de rotulação reside nesse poder:

na medida em que um grupo tenta impor suas normas a outros grupos da sociedade, encontra-se uma segunda questão: quais categorias são capazes, na prática, de obrigar outras a aceitar suas normas, $e$ quais são as causas do sucesso de um tal empreendimento? Evidentemente é uma questão de poder político e econômico (Becker, 1985, p. 40).

$\mathrm{O}$ aparecimento de um novo rótulo faz parte de um empreendimento moral ou burocrático, porém sua legitimação resulta do processo político e econômico. Estabelecido esse postulado, o autor situa o papel dos especialis- 
tas e dos serviços profissionais. Segundo Becker, "é de maneira seletiva que os representantes da lei, respondendo às pressões da própria situação de trabalho, aplicam a lei e criam as categorias de pessoas estranhas à coletividade" (Becker, 1985, p. 185).

Seria fundamental enfatizar que as teorias interacionistas clássicas, particularmente a da rotulação, suscitaram várias críticas. Por exemplo, para Faugeron,

\section{o interacionismo permanece freqüentemente uma doutrina puramente teórica, não exposta à pesquisa empírica ou somente de maneira fragmentada, sem construir nessa base um projeto de conjunto que seja operatório. Pode-se atribuir essa falha, em parte, a um defeito metodológico (Faugeron, 1976, p. 17).}

Nessa perspectiva, os interacionistas privilegiam o procedimento indutivo, que visa construir categorias de análise, em relação ao procedimento dedutivo observado nos trabalhos de sociólogos clássicos, como Durkheim. As críticas recebidas e o confronto com abordagens diversas incitaram os interacionistas a refletirem sobre o trabalho de campo e a utilizarem a observação in situ de maneira mais rigorosa. Becker é um dos principais autores a se preocupar com essa questão. Ele menciona que problemas de metodologia durante a pesquisa de campo devem ser enfrentados pelos pesquisadores através de um controle rigoroso do trabalho empírico. Segundo o autor, as categorias de análise construídas por procedimento indutivo permitem o recolhimento mais rigoroso de dados e a apresentação de descrições precisas e sistemáticas (cf. Becker, 1985). Tais princípios podem ser complementados pela delimitação de Chapoulie:

seria preciso, primeiro, insistir no fato que a unidade dessa corrente de pesquisa não repousa sobre a adesão a 'teorias', mas sobre um procedimento empírico, o trabalho de campo, com insistência na observação direta, e sobre uma abordagem original da sociedade concebida como conjunto de ações coletivas, que implica um interesse sustentado por certos aspectos da realidade social negligenciados por outras tradições mais 'positivistas' (como a tradição durkheimniana) (Chapoulie, 1985, p. 15).

A característica principal dessa corrente é um enfoque centrado no estudo de campo e na observação in situ das pequenas comunidades. Durand \& Weil observam que "a sociologia interacionista não procura provar as teorias através dos fatos objetivos, mas ser conivente com o que provêm" (Durand \& Weil, 1990, p. 172).

Autores como Downes \& Rock (1988) estimam que a corrente interacionista é "ambígua" e "evasiva", não parecendo científica na medida em que é um sistema fechado que resiste à contestação de pressupostos. Para 
os autores, os interacionistas clássicos ignoram as revisões de suas próprias concepções da sociedade ou escapam a elas. Assim, o estudo de um pequeno grupo de delinqüentes, por mais avançado que seja, seria insuficiente para fornecer verdades sobre os delinqüentes de maneira geral. Esse tipo de análise impede uma visão total do problema.

Outra crítica freqüentemente dirigida à teoria da rotulação é que ela "não fornece uma explicação etiológica do desvio (...) e não explica como aqueles que cometem os atos desviantes chegam a isso, nem porque alguns os cometem enquanto outros, em volta deles, se abstêm" (Becker, 1985, p. 202).

Nessa perspectiva, Faugeron observa que os comportamentos nãoconformes são geralmente definidos como desviantes antes do processo de rotulação através do qual o desvio é institucionalizado e legitimado. Ou seja, o desvio primário não é considerado pelos interacionistas. $\mathrm{O}$ autor explicita:

a reprovação mais séria diz respeito ao desvio primário. Explicando a amplificação secundária do desvio pelo efeito da reação social, o interacionismo deixa pendente o problema de saber de onde vem o desvio primário (Faugeron, 1976, p. 18).

Becker tentou responder ao conjunto dessas críticas através de uma visão retrospectiva da teoria da rotulação, publicada em 1973. Quanto à última observação, mencionada acima, o autor justifica:

...não importa qual seja a importância da operação de rotulação executada pelos empreendedores de moral, não se pode absolutamente considerá-la como a única explicação do que fazem de fato os desviantes. Seria absurdo sugerir que os ladrões à mão armada atacam as pessoas simplesmente porque alguém os rotulou com ladrões à mão armada, ou que tudo que faz um homossexual é decorrente do fato que alguém o rotulou como tal. Entretanto, uma das mais importantes contribuições desse enfoque foi chamar a atenção sobre as conseqüências que implicam, para um indivíduo, ofato de ser rotulado como desviante: torna-se mais dificil para ele prosseguir as atividades habituais de sua vida cotidiana, e essas dificuldades o incitam às ações 'anormais'(...) O grau em que o fato de ser qualificado de desviante conduz a essa conseqüência deve ser estabelecido em cada caso, por um procedimento empírico e não por um decreto teórico (Becker, 1985, p. 203).

Apesar das críticas suscitadas, o interacionismo traz uma contribuição original quanto ao papel dos "construtores" e/ou "legitimadores" do desvio. Como diz Becker, os fenômenos do desvio podem unir de forma estreita "a pessoa que emite o julgamento do desvio, o processo que chega a 
esse julgamento e a situação dentro da qual ele é produzido" (Becker, 1985, p. 203). No item seguinte serão comentadas algumas análises relacionadas a ou compatíveis com os estudos interacionistas citados acima.

\section{Correntes relacionadas ao interacionismo}

A teoria interacionista clássica diversificou-se em várias orientações a partir do final dos anos 60. Além disso, outros sistemas de análise do fenômeno do desvio apareceram nos anos 70 com o objetivo de estudar, além das interações cotidianas, os modos de dominação e a influência das relações de poder na sociedade. Uma análise detalhada dessas diferentes idéias ultrapassaria o objetivo presente. Será apresentado apenas um comentário sintético de algumas tendências para testemunhar suas contribuições.

Alguns autores citam as perspectivas "conflituais" como complementares às teorias interacionistas do desvio (cf. Conrad \& Schneider, 1980). De acordo com essa corrente, os rótulos são o produto dos conflitos políticos e sociais: num enfoque macro-social, a realidade social é baseada nos interesses políticos e econômicos de certos grupos e na visão da classe que se encontra no poder. O controle social seria um mecanismo utilizado por certos grupos para dominar outros.

Essa tendência faz parte da "criminologia radical", corrente que surgiu nos anos 70 e dentro da qual observa-se o aparecimento de uma perspectiva de inspiração marxista, onde o conflito é encarado como o produto da estrutura de classe de uma sociedade e das relações dos indivíduos com o sistema econômico. Os trabalhos de Taylor (1973 apud Downes \& Rock, 1988) mostram essa análise baseada numa sociologia da estruturação social e na ideologia.

Para os seguidores dessa corrente, o marxismo deve ser dissociado do Estado Socialista Soviético para ser repensado como uma força crítica. As teorias marxistas são então reinterpretadas com a finalidade de tentar analisar as crises emergentes, a inabilidade do capitalismo para resolvê-las e a inevitabilidade de conflitos novos e mais devastadores (cf. Downes \& Rock, 1988).

No seu conjunto, a perspectiva "conflitual" se interessa pela desigualdade dos indivíduos numa sociedade no que diz respeito ao poder de construir a realidade social. Ela sustenta que o desvio e a rotulação dos desviantes são criados por um tipo de conflito entre grupos distintos e que servem aos interesses políticos e econômicos daqueles que têm mais poder (cf. Conrad \& Schneider, 1980).

Outras orientações compatíveis com o interacionismo clássico foram desenvolvidas. Dois exemplos significativos são a fenomenologia e a etnometodologia. Apesar de algumas nuances, essas duas correntes apresentam vários pontos comuns. Um deles é que os rótulos são socialmente construídos através das interações, sendo a linguagem um modo fundamental de construção da realidade. Tais análises chamam atenção para o fato que, nas construções sociais baseadas na linguagem, da mesma maneira que os rótulos 
são construídos e/ou legitimados pelos atores sociais, eles podem ser modificados pelos mesmos (cf. Conrad \& Schneider, 1980).

A orientação fenomenológica é principalmente representada por Schutz (1987 apud Durand \& Weil, 1990). O autor menciona a inter-subjetividade como um fato constitutivo do mundo social, situando-a entre o objetivismo e o subjetivismo. A partir desses princípios, Schutz examina a relação entre os diferentes atores na vida cotidiana. Seu objetivo é compreender o ator em suas ações, seus sentimentos e o estado de espírito que incitouo a adotar atitudes específicas em seu meio social. $\mathrm{O}$ autor procura descrever e explicar as experiências do observador, analisando sua própria significação do mundo social, assim como as do ator tal qual se pode observar e da forma que ele se deixa perceber.

A etnometodologia se inspira na fenomenologia e na análise da linguagem cotidiana. Seu objetivo fundamental é perceber a análise das significações empreendidas pelos próprios atores. Garfinkel (1967) e Cicourel ([1972] 1979) são os principais representantes dessas idéias. Seria conveniente também citar Goffman (1971; [1967] 1974; [1981] 1987 apud Durand \& Weil, 1990), pela importância de seus trabalhos sobre a análise da conversação. No exemplo seguinte, o modelo teatral proposto pelo autor é reafirmado:

vou então afirmar que a vida social é uma cena, não numa grande proclamação literária, mas de forma simplesmente técnica: a saber que, profundamente incorporadas à natureza da palavra, encontram-se as necessidades fundamentais da teatralidade (Goffman, 1987, p. 10).

O modelo de análise dos etnometodologistas supõe que o mundo social é construído e interpretado através da linguagem. As categorias de linguagem trocadas durante as interações sociais fornecem significações ordenadas das experiências individuais e da vida em sociedade.

Para Garfinkel (1967) é essencial realizar uma análise interna da ordem social utilizando-se o saber veiculado pelos próprios atores. Segundo o autor, o saber imanente às práticas lhes confere três características: a) reflexibilidade (o discurso sobre a ação, pelos atores); b) descritibilidade (a inteligência das práticas se produz em situação e as torna visíveis, racionais e relatáveis); c) indexicalidade (para ser inteligível, a linguagem deve ser indexada a uma situação ou a um indivíduo) (cf. Durand \& Weil, 1990). As análises de Garfinkel sobre as práticas sociais favorecem, portanto, o estudo sociológico da linguagem cotidiana e dos problemas associados à conversação como interação.

Uma das principais críticas suscitadas pelos trabalhos de Garfinkel relaciona-se aos riscos que comporta uma análise restrita à área da linguagem. Nesse sentido, o procedimento etnometodológico pode ser colocado em questão visto que a ação é encarada prioritariamente como o resultado de regras interpretativas próprias à comunicação. Como observa Bourdieu, a etnometodologia tende a tornar-se "uma semiologia idealista que, dando-se por 
objeto fazer um 'relatório' dos 'relatórios"”, acaba "registrando os registros de um mundo social que, no limite, seria o produto de estruturas mentais, ou seja, lingüísticas" (Bourdieu, 1979, p. 562 apud Durand \& Weil, 1990, p. 182).

Cicourel (1979) estuda o enfoque etnometodológico na sociologia cognitiva. Para compreender o diálogo cotidiano, o autor busca reunir as idéias interacionistas, a etnometodologia e a análise da conversação. Cicourel tenta compreender como os indivíduos podem dominar os processos interacionais e como um papel é construído pelo ator durante as interações. Para atingir tal objetivo, o autor tenta explicar a sociedade utilizando um modelo lingüístico. Para ele, a compreensão da linguagem falada exige uma informação não-verbal; dessa maneira, o diálogo cotidiano funciona em vários registros, principalmente devido às estruturas extra-lingüísticas. A sociologia cognitiva é assim interpretada como um modo de unir o conhecimento e as configurações sociais e estruturais de uma sociedade (cf. Durand \& Weil, 1990).

As críticas dirigidas aos etnometodologistas dizem respeito essencialmente à redução a uma análise das ações individuais observadas nas interações cotidianas. Os seguidores dessa corrente negligenciam a influência da imposição do poder assegurado pela mediação das instituições. Bourdieu, por exemplo, afirma que com os etnometodologistas pode-se encontrar aspectos essencialmente subjetivistas. Segundo o autor,

por um lado, as estruturas objetivas que o sociólogo constrói no momento objetivista, afastando as representações subjetivas dos agentes, são o fundamento das representações subjetivas e elas constituem as obrigações estruturais que pesam sobre as interações; mas por outro lado, essas representações devem também ser retidas, se quisermos tomar conhecimento das lutas cotidianas, individuais ou coletivas, que visam transformar ou conservar essas estruturas. Isso significa que os dois momentos, objetivista e subjetivista, estão numa relação dialética e que, mesmo se, por exemplo, o momento subjetivista parece muito próximo quando o pegamos separadamente, nas análises interacionistas ou etnometodológicas, ele está separado por uma diferença radical: os pontos de vista são apreendidos como tais e relacionados às posições na estrutura dos agentes correspondentes (Bourdieu, 1987, p. 150).

Embora as tendências etnometodológicas e fenomenológicas privilegiem um enfoque das interações focalizado na linguagem e na experiência individual dos atores, negligenciando as condições estruturais da sociedade, é importante considerar a contribuição dessas idéias no que diz respeito à análise das práticas sociais e dos papéis construídos e representados no curso das interações. 
Pode-se reafirmar aqui o caráter redutor da oposição objetivismo/ subjetivismo, apontado por Bourdieu. Para o autor, é fundamental considerar a análise da estrutura social e a organização da experiência, a qual tem sua própria coerência. De acordo com Bourdieu, as estruturas internas da subjetividade e as estruturas sociais externas são dois estados da mesma realidade e da mesma história coletiva (cf. Lima, 1998).

Os trabalhos citados nesse item mostram que o desvio pode ser entendido através da compreensão das atitudes dos atores para com o meio social e das significações que eles próprios dão a seus atos. Porém, seria essencial ampliar as correntes fenomenológicas e etnometodológicas para além da esfera individual, considerando-se os mecanismos sociais que determinam os discursos e as práticas dos atores.

Para finalizar, enfatiza-se a contribuição das teorias interacionistas do desvio, particularmente a "teoria da rotulação" (labelling theory), que propuseram um rompimento com outras correntes que privilegiam as causas do fenômeno e não o processo social através do qual ele ocorre na sociedade. Porém, é fundamental considerar que as interações entre atores ou grupos sociais relacionam-se à ordem moral, política, socioeconômica da sociedade. O desvio e a rotulação de indivíduos ou grupos sociais dependem da maneira que o fenômeno é vivido em cada sociedade, num dado momento histórico e social. $\mathrm{Na}$ realidade, é um conjunto de operações materiais e simbólicas que dá sentido às práticas e governa as ações dos atores, no plano individual e social.

Recebido para publicação em agosto/2000

LIMA, Rita de Cássia Pereira. Sociology of deviance and interactionism. Tempo Social; Rev. Sociol. USP, S. Paulo, 13(1): 185-201, May 2001.

ABSTRACT: This is essentially a theoretical article and it aims to present a nonexhaustive analysis of the sociology of deviance, emphasizing interactionist theories. A brief account of the emergence of the sociology of deviance in Chicago is followed by a discussion on three tendencies that are involved in analyzing the causes of deviance: functionalism, anomie and culturalism. Next, interactionism arises as a means to break up with the causal approach. The specificity of the interactionist theory, especially H. Becker's Labelling Theory, can be seen in collective action and in the emphasis on the social process through which an individual or a group is considered deviant by the others. Finally, a few of the more recent tendencies are mentioned, such as phenomenology and ethnomethodology, and the criticism directed at these theories, mainly by Pierre Bourdieu, are discussed.

KEY WORDS: sociology of deviance, interacionism, labelling theory. 


\section{REFERÊNCIASBIBLOGRÁFICAS}

BECKER, Howard S. (1985) Outsiders . 1 a edição 1963. Paris, A. M. Metailié.

Boudon, Raymond \& BourRICAud, François. (1982) Dictionnaire critique de la sociologie. Paris, PUF.

BouRdieu, Pierre. (1979) La distinction: critique sociale du jugement. Paris, Minuit. . (1987) Choses dites. Paris, Minuit.

Chapoulie, Jean-Michel. (1985) Prefácio. In: BeCKer, Howard. S. Outsiders. $1{ }^{a}$ e edição 1963. Paris, A. M. Metailié.

Crcourel, Aaron. (1979) La sociologie cognitive. 1 1e edição 1972. Paris. P.U.F.

Cloward, Richard \& Ohlin, Lloyd. (1960) Delinquency and opportunity, New York.

Cohen, Albert K. (1955) Delinquent boys: the culture of the gang. Glencoe.

CONRAD, Peter \& SCHNEIDER, Joseph. (1980) Deviance and medicalizationfrom badness to sickness. Saint-Louis, The Mosby Company.

Coulon, Alain. (1992) L'école de Chicago. Paris, PUF. (Col."Que sais-je?" $\left.\mathrm{n}^{\circ} 2639\right)$.

Downes, David \& Rock, Paul. (1988) Understanding deviance: a guide to the sociology of crime and rule-breaking. $1^{\mathrm{a}}$ edição 1982. Oxford, Clarendon Press.

DURAND, Jean-Pierre \& Weil, Robert. (1990) Sociologie contemporaine. Paris, Vigot.

DuRKheIn, Emile. (1967) De la division du travail social. 1ª edição 1893. Paris, PUF. . (1960) Le suicide - étude sociologique. 1a edição 1897. Paris, PUF.

Faugeron, Claude et alii. (1976) De la deviance et du controle social (représentations et attitudes). Paris, Presses de COPEDITH.

GARFINKEL, Harold. (1967) Studies in ethnomethodology. Englewood Cliffs, Prentice Hall.

Goffman, Erving. (1971) Les relations en public. Paris, Minuit. . (1974) Les rites d'interaction. 1ª edição 1967. Paris, Minuit. . (1987) Façons de parler. 1ª edição 1981. Paris, Minuit.

LEMERT, Edwin M. (1951) Social pathology, New York, Mc Graw Hill.

Lima, Rita C.P. (1994) Le processus d'élaboration de diagnostics sur les enfants et adolescents 'abandonés', 'infracteurs' et 'assistés' par les équipes interdisciplinaires de la Fondation de l'Etat du BienEtre du Mineur de São Paulo - Brésil. 538 p. Tese (Doutorado). 
Université René Descartes - Paris V-Sorbonne. . (1998) A "violência simbólica" de Pierre Bourdieu. Serviço social \& sociedade, São Paulo, 57: 166-183, julho.

Malinowsky, Bronislaw. (1988) Une théorie scientifique de la culture. $1^{\mathrm{a}}$ edição 1944. Paris, Maspero.

MEAD, Georges Herbert. (1963) L'esprit, le soi et la société. 1ª edição 1934. Paris, PUF.

Merton, Robert K. (1965) Eléments de théorie et de méthode sociologique. $1^{\mathrm{a}}$ edição 1953. Paris, Plon.

PARK, Robert E. \& Burgess, Ernest W. (1979) L'école de Chicago: naissance de l'écologie urbaine. 1a edição 1925. Paris, Aubier, Champ urbain.

Schutz, Alfred. (1987) Le chercheur et le quotidien. Paris, Méridiens Klinsieck.

SElosse, Jacques. (1981) Regards sur les problématiques des recherches concernant la délinquance juvénile. Connexions, Paris, 32: 11-30.

Sutherland, Edwin \& CRessey, Donald R. (1966) Principes de criminologie. 1a edição 1924. Paris, Cujas.

TAYLOR, Ian et alii. (1973) The new criminology, for a social theory of deviance. London, Routledge. 